Manuscript

\title{
Design and performance analysis of a regenerative evaporative cooler for cooling of buildings in arid climates
}

\author{
Rabah Boukhanouf a, Omar Amer a, Hatem Ibrahim ${ }^{\text {b }}$, and John Calautit a \\ a Department of Architecture and Built Environment, University of Nottingham, Nottingham, NG7 2RD, UK \\ b Department of Architecture and Urban Planning, Qatar University, Doha, Qatar
}

Corresponding author. e-mail: rabah.boukhanouf@nottingham.ac.uk

\begin{abstract}
Evaporative cooling has been considered a low energy consumption process that often is associated with displacement ventilation and passive cooling strategies of buildings. While significant energy savings can be accrued from using evaporative cooling, there are many design challenges to improve the processes of heat and mass transfer and reduce design complexities. This paper seeks to advance the design of evaporative cooling through building and testing a novel regenerative evaporative cooler prototype. It proposes a design that integrates heat pipe and porous ceramic tube modules as an alternative to plate heat exchangers. The paper describes design arrangement of the cooler, a mathematical model and laboratory test results. Under controlled laboratory test conditions, the measured performance indices of wet bulb effectiveness, specific cooling capacity and coefficient of performance (COP) were determined as $0.8,140 \mathrm{~W}$ per $\mathrm{m}^{2}$ of wet ceramic surface area and 11.43 respectively. Furthermore, experimental results show that under typical ambient conditions commensurate with that prevailing in arid climates, the cooler air supply temperature was as much as $14{ }^{\circ} \mathrm{C}$ below that of the ambient air.
\end{abstract}

\section{Key words}

Regenerative evaporative cooling, building technology, computer modelling, Porous ceramic materials 


\section{Introduction}

The spread of low cost packaged domestic air conditioning systems (window mounted and split systems) for space cooling of buildings is driven by growth in world population, increased urbanisation, and poor building construction standards, particularly in developing countries. Coupled with reduced performance of mechanical air conditioning system in hot climates, energy consumption in building makes up to $50 \%$ (rising to $70 \%$ in typical mid-afternoon summer day) of total demand for power [1]. Inevitably, this has often affected electricity grids' reliability and exerted pressure on public authorities to invest in more power generation capacity. In addition, conventional air conditioning systems contribute to greenhouse gas emission, pollution and carry health risks such as allergies and asthma for building occupants [2].

Commonly evaporative cooling systems are found in hot and dry climates (e.g., parts of the USA, Middle East, India, etc.) where they operate most effectively. $[3,4]$. These systems are capable of providing adequate thermal comfort for building occupants and better indoor air quality through displaced ventilation and supply of fresh outdoor air.

The principle of water evaporation, to generate a cooling effect through the exchange of sensible and latent between surrounding air and a wet surface, is applied in the design of cooling towers, evaporative condensers, and direct and indirect evaporative cooling systems for thermal comfort application in buildings. For example, in direct evaporative coolers (DEC), supply air is forced through a wet media material, reducing the air temperature while increasing its moisture content. In indirect evaporative coolers (IEC), a plate heat and mass exchanger (HMX) is deployed to create separate airflow channels through which the supply (dry) and working (wet) air exchange sensible heat without mixing.

Recent research is directed at improving designs of indirect evaporative cooling systems for their advantage of cooling air without increasing the moisture content. The introduction of the M-cycle concept offered further enhancement of indirect evaporative cooling designs and performance [5]. The core element of M-cycle designs is a compact plate heat and mass exchanger (HMX), which is formed of thin sheets sealed at the edges in a particular arrangement to provide multi-cross flow paths in the dry and wet channels [6], as shown in Fig. 1 (a). Other HMX configurations known as regenerative indirect evaporative coolers (Fig. 1(b)) were also developed to enhance thermal performance by arranging airflows in counterflow. [7, 8]. In practice, these compact HMXs are manufactured as a sealed core component made of a large number of edge-welded synthetic plastic plates.
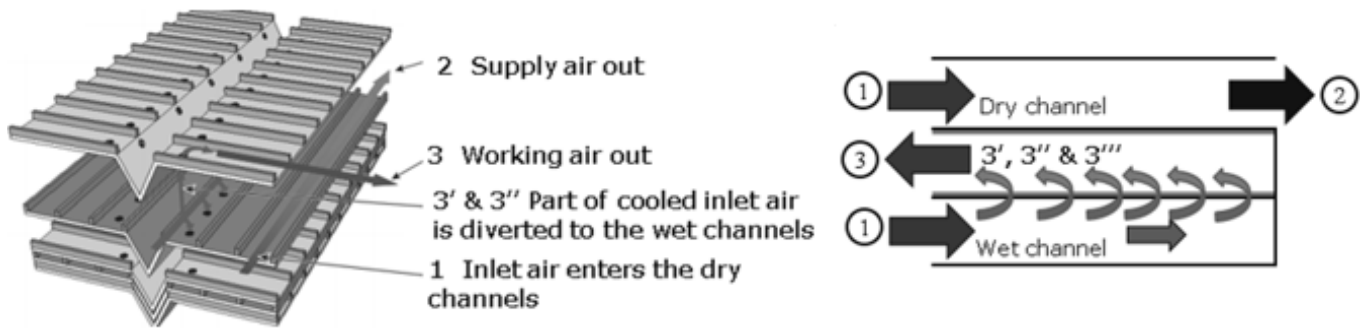

(a) 

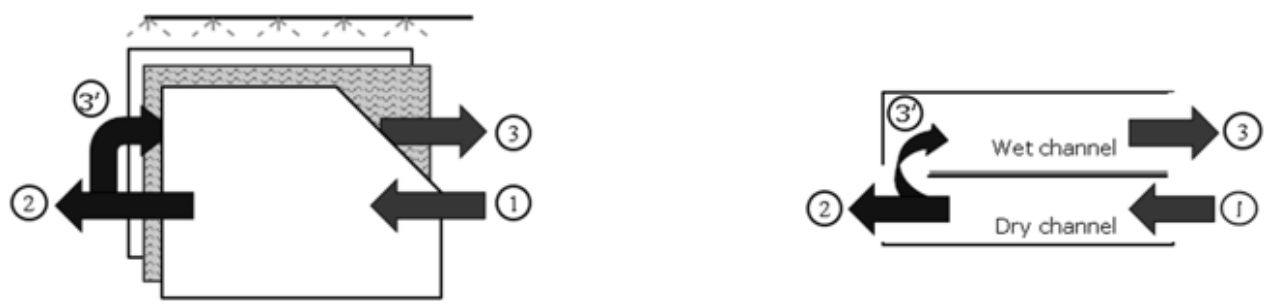

(b)

Fig. 1 Construction and airflow patterns of a) M-cycle b) regenerative counter flow IEC systems

The development of evaporative cooling systems have been extensively reported in a number of review and research papers. Table 1 summarises recent studies on regenerative evaporative coolers equipped with different types of heat and mass exchangers (HMX), orientation and thermal performance indices

Table 1 Design and development of sub-wet bulb indirect evaporative cooling systems

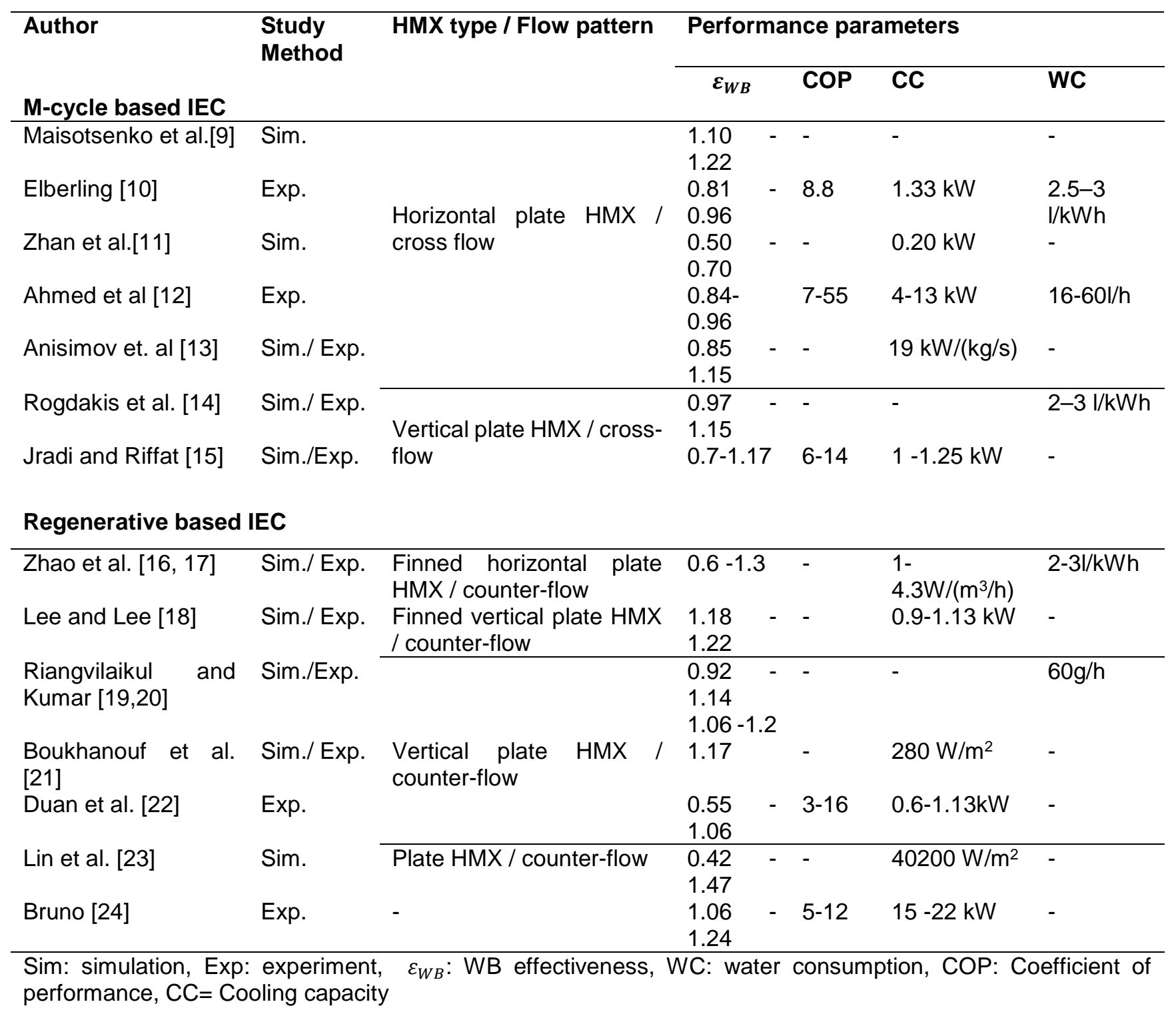


The focus of research in most designs of Table 1 is the optimisation of HMX geometry, heat and mass transfer and properties of materials. In addition, it was shown in many works that experimental and theoretical results converge on a range of HMX specification parameters such as air channels height of about $5 \mathrm{~mm}$, length of $1 \mathrm{~m}$, airflow velocity of $1 \mathrm{~m} / \mathrm{s}$ and working to product air flow rate ratio of $0.3-0.5$. It is also worth mentioning that the experimental results of many studies reported WB effectiveness lower than 1 was achieved while simulation results show higher WB effectiveness (1 to 1.4). This discrepancy is often related to the design characteristics of the HMX where water distribution and wettability of porous media are difficult to replicate in simulation models $[25,26]$.

There is little published work on the durability and serviceability of this type of HMXs. For instance, the use of organic materials such as weaved fibrous textile fabrics and Kraft paper for water retention may affect the heat transfer performance [27]. The closely packed and edge welded plates create narrow air passages with high pressure loss and susceptibility to clogging through dust build up and mould spore growth within the core. Furthermore, over time damage to the core plates may cause short air paths between the wet and dry channels leading to supply air contamination.

Other researchers considered more rigid porous materials as wet media in evaporative cooling systems. This is particularly appropriate for integration of evaporative cooling with a building envelope. Schiano-Phan and Ford [28] used direct evaporative ceramic panels as part of a building wall for cooling. He and Hoyano [29] also built and tested a passive evaporative cooling wall for open urban areas, which is made of high water absorption porous ceramic pipes. It was found that the system reduces the surrounding air temperature by $2{ }^{\circ} \mathrm{C}$.

Similarly, Riffat and Zhu [30,31] introduced a building-integrated indirect evaporative cooling system using heat pipes and porous water containers for heat transfer between the dry and wet air ducts. The large volume of water containers and mounting the heat pipes in a horizontal orientation may have affected the overall thermal performance of the design. Likewise, Wang et al. [32] used a similar configuration with the heat pipe condenser wrapped around a water-sprayed absorbent layer. The experimental results showed that effectiveness of 0.70 could be achieved although high water consumption rate was also recorded.

\section{Objective}

Many studies have been conducted on evaporative cooling design and development, performance evaluation and applications with the focus on space cooling in buildings. In this context, this work attempts to advance further design and thermal performance of regenerative evaporative cooling systems. The research methodology approach consists of design, mathematical modelling and testing the performance of a small-scale laboratory prototype under various operating climatic conditions. It describes the design parameters and configuration of the system's components, the formulation of a mathematical model and controlled laboratory testing conditions. Furthermore, it reports on modelling and test results and the overall measured performance and validation of the model. 


\section{Overview of the evaporative cooler design}

A regenerative evaporative cooler typically consists of a dry and wet air channel separated by a heat transfer membrane, an air circulating fan, a water supply system, and other ancillaries. The proposed evaporative cooler uses a modular vertically mounted heat pipes and porous ceramic tubes that form the heat and mass exchanger. A schematic diagram of the cooler is shown in Fig. 2(a). A single heat and mass exchanger module comprises a wicked tubular heat pipe with its finned evaporator located in the dry channel and condenser protruding into the wet channel. A porous ceramic tube is then fitted as a sleeve over the condenser part of the heat pipe, as shown in Fig. 2(b). In operation, the annulus gap between the heat pipe and the ceramic sleeve is filled with water, which allows the porous ceramic sleeve to be continuously saturated and form a thin water film on its external surface.

The ambient hot, dry air at the inlet of the dry channel (state 1) is circulated over the finned part of the heat pipe, decreasing its temperature along the channel. At the outlet of the dry channel (state 2), part of the dry and cool air (product air) is diverted into the wet channel (state 3) where it flows over the wet ceramic tubes and causes water to evaporate, removing heat deposited at the heat pipe condenser before being discharged as saturated air to outside (state 4). The process thus permits to achieve the greatest temperature drop of product air while rejecting humid working air.

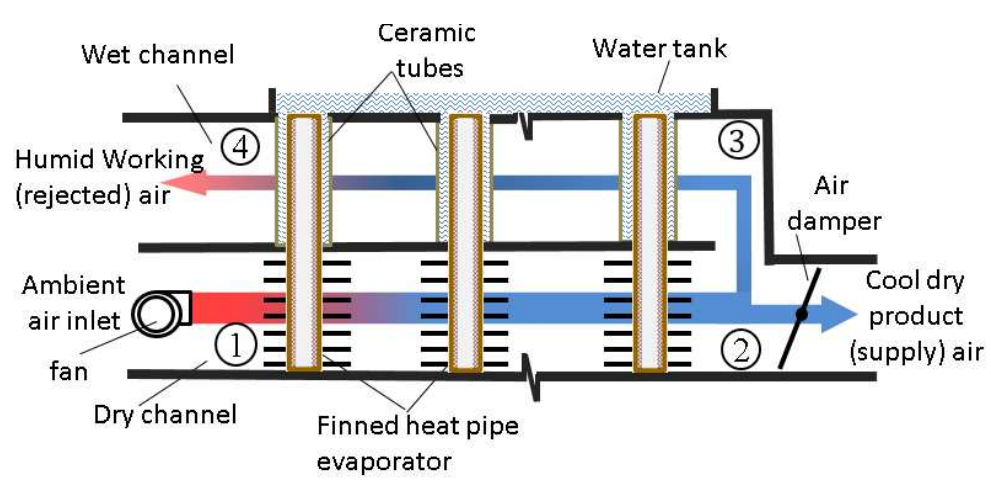

(a)

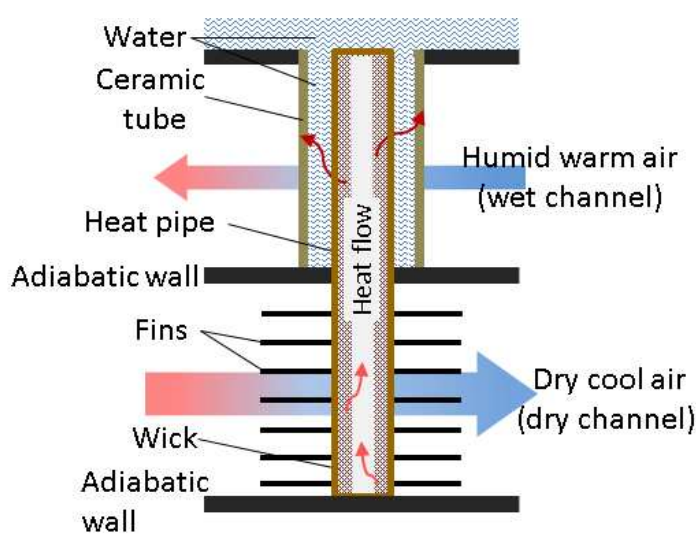

(b)

Fig. 2 a) Schematic of the cooler configuration and working principle b) Structure of heat pipe-ceramic tube module

Compared to compact plate HMXs, the integrated heat pipes-porous ceramic tube is modular and of rigid structure. Porous ceramics are also structurally stable materials, widely available and recyclable. Depending on the porosity, which is controlled through the firing temperature, ceramic materials have high contact surface area and wicking capability that allow uniform wettability. Equally, heat pipes are passive thermal devices with high heat transfer properties. They are hermetically sealed tubes that contain a small amount of a two-phase fluid such as de-ionised water which evaporation and condensation transports large quantities of heat from one end (evaporator) to the other (condenser). For this work, gravity assisted capillary-driven standard tubular heat pipes were selected as they provide higher thermal performance and widely available in standard sizes. 
This work however did not consider the economic feasibility of the system beyond the cost of purchasing individual components for constructing and testing the thermal performance of the small-scale laboratory prototype. Nevertheless, the proposed design offers many financial and environmental advantages including low maintenance cost, long life of core components, no environmentally polluting Polyvinyl Chloride (PVC) materials in core components, and easy to manufacture and assemble.

\section{Computer modelling}

Many operating parameters and conditions should be established prior to estimate the cooling performance of the cooler. The ambient air conditions such as dry bulb temperature and moisture content are required to work out the range of expected supply air conditions. The geometrical configuration and size of airflow channels, heat pipe heat transfer capability and ceramic tubes wet area are also required for the computer model to determine the thermal performance of the system.

The formulation of the mathematical model was based on the principles of heat and mass transfer taking place in the system. The heat transport limiting factors of heat pipes (entrainment, capillary, boiling, sonic, and viscous) were considered from the manufacturer specification. In the model, the air channels are divided into equally spaced discrete control volumes with each control volume enclosing a single heat pipe-ceramic tube module, as shown in Fig. 3(a). An enlarged section of a single control volume is shown in Fig. 3(b), where all input and output parameters are shown.

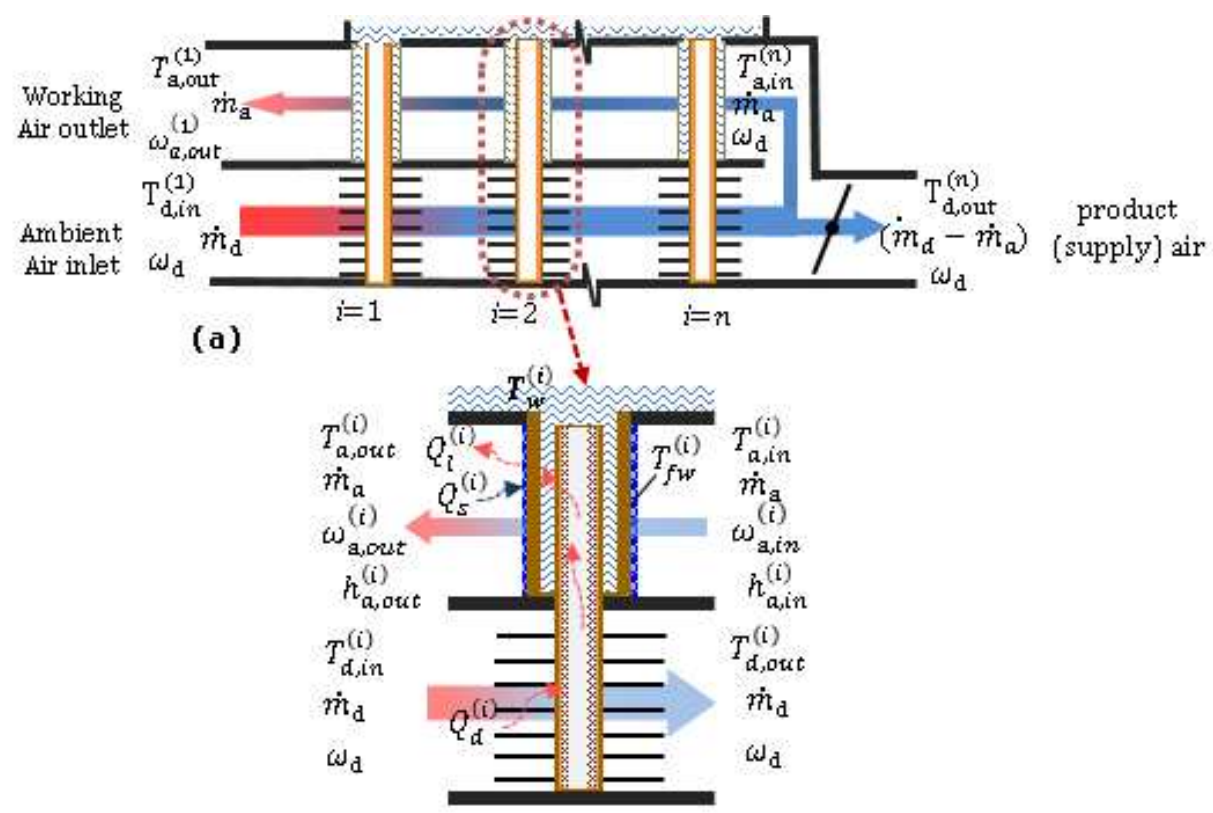

(b)

Fig. 3 a) Computational model control volumes representation b) Model parameters of a single module 
The heat and mass transfer process of a regenerative evaporative cooling system is complicated by many factors. The cooling performance of the system can be affected by ambient air temperature, relative humidity, air and water flow rate and a physical dimension. To simplify the model formulation, it was assumed that steady state of heat and mass transfer and fluid flow rates are fully established, the outer case wall is adiabatic, the water film thickness on the porous ceramic is uniform and small, and the water-air interface temperature is equal to the water film temperature [33]. The underpinning equations of heat and mass transfer processes in the cooler are summarised in the following section.

\subsection{Dry channel overall heat transfer coefficient}

The incremental sensible heat transported by a single heat pipe-ceramic tube module from the dry channel to the wet channel can be expressed as:

$Q_{d}^{(i)}=-U_{\mathrm{d}}^{(i)} A_{d}^{(i)}\left(\mathrm{T}_{\mathrm{d}}^{(i)}-T_{\mathrm{wf}}^{(i)}\right)$

where, $A_{d}^{(i)}$ is the total heat transfer area of the finned evaporator section, $\mathrm{T}_{\mathrm{d}}^{(i)}$ is the dry channel control volume average temperature, $T_{\mathrm{wf}}^{(i)}$ is the wet surface average temperature and, $U_{\mathrm{d}}^{(i)}$ is the overall heat transfer coefficient. The overall heat transfer coefficient was evaluated from thermal resistances between the airflow in the dry channel and the water film on the surface of the porous ceramic in the wet channel as follows:

$$
U_{\mathrm{d}}^{(i)}=\frac{1}{\sum R_{t}}=\frac{1}{R_{1}+R_{H P}+R_{2}}
$$

where $R_{1}, R_{H P}$ and $R_{2}$ are the convective thermal resistance in the dry-air channel, overall heat pipe thermal resistance and wet channel thermal resistance respectively. The calculation of the heat pipe thermal resistance, $R_{H P}$, was adapted from the simplified thermal resistance model suggested by Reay et al. [34], in which the vapour path the thermal resistance and heat conduction along the wall were neglected. It is well known that the heat transport capability of a heat pipe is bounded by entrainment, capillary, boiling, sonic and viscous upper limits. In this design, the maximum heat transfer rate of a single heat pipe module was taken as the minimum value of those limits as specified by the manufacturer and expressed as follows [34]:

$\delta Q_{d}^{(i)}=\min \left(Q_{e}^{(i)}, Q_{c}^{(i)}, Q_{b}^{(i)}, Q_{s}^{(i)}, Q_{v}^{(i)}\right)$

where $Q_{e}^{(i)}$ is the entrainment limit, $Q_{c}^{(i)}$, is the capillary limit, $Q_{b}^{(i)}$, is the boiling limit, $Q_{s}^{(i)}$ is the sonic limit and $Q_{v}^{(i)}$, is the viscous limit.

\subsection{Energy and mass conservation model}

The governing laws of energy and mass conservation were applied over the control volume presented in Fig. 3(b) and a set of one-dimensional equations were developed to compute the product and working air temperature and moisture content. The energy balance depicting heat transfer between the dry and wet channel in a single control volume can be written as: 
$\dot{m}_{\mathrm{d}} c_{P, \mathrm{~d}}\left(T_{d, \text { in }}^{(i)}-T_{d, \text { out }}^{(i)}\right)=-U_{\mathrm{d}}^{(i)} A_{d}^{(i)}\left(\mathrm{T}_{\mathrm{d}}^{(i)}-T_{\mathrm{wf}}^{(i)}\right)$

where $T_{d, \text { in }}^{(i)}$ and $T_{d, \text { out }}^{(i)}$ are the control volume inlet and outlet temperature of the dry channel and $\dot{m}_{\mathrm{d}}$ and $c_{P, \mathrm{~d}}$ are the air mass flow rate and specific heat capacity respectively.

Similarly, the water vapour mass transfer balance between the surface of the wet porous ceramic and bulk airflow in the wet channel can be expressed as:

$\dot{m}_{\mathrm{a}}\left(\omega_{\mathrm{a}, \text { out }}^{(i)}-\omega_{\mathrm{a}, \mathrm{in}}^{(i)}\right)=\sigma_{m}^{(i)} A_{a}^{(i)}\left(\omega_{\mathrm{wf}}^{(i)}-\omega_{\mathrm{a}}^{(i)}\right)$

Where $\omega_{a, \text { in }}^{(i)}$ and $\omega_{a, \text { out }}^{(i)}$ are the control volume inlet and outlet air moisture content, $\dot{m}_{\mathrm{a}}$ is the working fluid mass flow rate in the wet channel and $\sigma_{m}$ is the mass transfer coefficient, $A_{a}^{(i)}$ is the water film surface area, and $\omega_{\mathrm{a}}^{(i)}$ and $\omega_{\mathrm{wf}}^{(i)}$ are bulk air and saturation air moisture content respectively.

Assuming Lewis Number $\left(L_{e}=U_{a} / \sigma_{m} c_{p, a}\right)$ to be close to 1 , as it ranges between 0.9 and 1.15 for most water-air systems, and the specific heat capacity of moist air is expressed as $c_{P, a}=c_{P, d}+\omega c_{P, v}$, the wet channel control volume energy conservation can written as follows [31]:

$\dot{m}_{\mathrm{a}} c_{\mathrm{P}, \mathrm{a}}\left(T_{\mathrm{a}, \text { out }}^{(i)}-T_{a, \text { in }}^{(i)}\right)=U_{\mathrm{a}}^{(i)} A_{a}^{(i)}\left(\mathrm{T}_{\mathrm{wf}}^{(i)}-T_{\mathrm{a}}^{(i)}\right)$

where $\mathrm{T}_{\mathrm{a}}^{(i)}$ is the bulk air temperature. $T_{a, i n}^{(i)}$ and $T_{a, o u t}^{(i)}$ are inlet and outlet temperature respectively.

Finally, it is necessary to verify that the entire control volume energy is balanced out. This is can be expressed as:

$\dot{m}_{\mathrm{w}}^{(i)}\left(h_{\mathrm{wf}, \mathrm{out}}^{(i)}-h_{w f, i n}^{(i)}\right)=-U_{\mathrm{d}}^{(i)} A_{d}^{(i)}\left(\mathrm{T}_{\mathrm{d}}^{(i)}-T_{\mathrm{wf}}^{(i)}\right)-\sigma_{m}^{(i)} A_{a}^{(i)}\left(\omega_{\mathrm{wf}}^{(i)}-\omega_{\mathrm{a}}^{(i)}\right) h_{f g, w f}-U_{\mathrm{a}}^{(i)} A_{a}^{(i)}\left(\mathrm{T}_{\mathrm{wf}}^{(i)}-T_{\mathrm{a}}^{(i)}\right)$

where, $h_{w f, i n}^{(i)}$ and $h_{w f, o u t}^{(i)}$ are inlet and outlet water specific enthalpy, $h_{f g, w f}$ is specific latent heat of water vaporisation and $\dot{m}_{\mathrm{w}}^{(i)}$ is water flow rate which is equal to the amount of water evaporation from the surface of the porous ceramic tube of the control volume, $\dot{m}_{\mathrm{a}}\left(\omega_{\mathrm{a}, \text { out }}^{(i)}-\omega_{\mathrm{a}, \mathrm{in}}^{(i)}\right)$.

The formulated mathematical equations (4) to (7) embrace such key variables as airflows, heat and mass transfer coefficient, temperature and moisture content and shape of the components of the regenerative evaporative cooler. They are particularly critical in that they enable to predict the steady state operating parameters of the system such as supply air temperature, cooling capacity and overall effectiveness.

\subsection{Boundary conditions}


A set of initial and boundary conditions was adopted for the solution of the mathematical model. The initial conditions assume air temperature and moisture content in all control volumes are in equilibrium with ambient conditions.

As the cooler uses ambient fresh air as intake to cool occupied building space through air displacement, the inlet air dry-bulb temperature and moisture content in the dry channel, $(i=1)$, are considered equal to prevailing ambient conditions. This can be written as:

$T_{d, i n}^{(1)}=T_{d, o}$ and $\omega_{d, i n}^{(1)}=\omega_{d, o}$

From the mechanical arrangement of the cooler, it can be seen that inlet air temperature and moisture content of the wet channel $(i=n)$ are equal to those of the airflow at the outlet of the dry channel. This is can be given as:

$T_{a, n}^{(n)}=T_{d, n}^{(n)}$ and $\omega_{a, n}^{(n)}=\omega_{d, n}^{(n)}$

Finally, since only a portion of the product air in the dry channel is diverted to the wet channel, a mass flow rate ratio of working to product air, $\alpha=\frac{\dot{m}_{a}}{\dot{m}_{d}}$ was also used as an important parameter in the optimisation of the performance of the cooler. A set of initial and boundary conditions of ambient temperatures, relative humidity and flow rate ratios used in this simulation is summarised in Table 2.

Table 2 boundary conditions

\begin{tabular}{ll}
\hline Boundary condition parameter & value \\
\hline Ambient air temperature, $\left({ }^{\circ} \mathrm{C}\right)$ & 30,35 and 40 \\
Ambient air relative humidity, $(\%)$ & 25,35 , and 45 \\
Product (dry channel) airflow rate, $\left(\mathrm{m}^{3} / \mathrm{h}\right)$ & 150 \\
Working to product air flow ratio, $(-)$ & $0.25,0.5$ and 0.75 \\
\hline
\end{tabular}

\subsection{Computational algorithm}

A computer algorithm was developed as shown by the flow chart of Fig. 4. The mathematical model (Equation (1) to (7)) and boundary conditions Equation (8) and (9) were discretised into a set of algebraic equations using finite difference method to predict the supply air temperature, flow rate, and other performance indices of the system. 


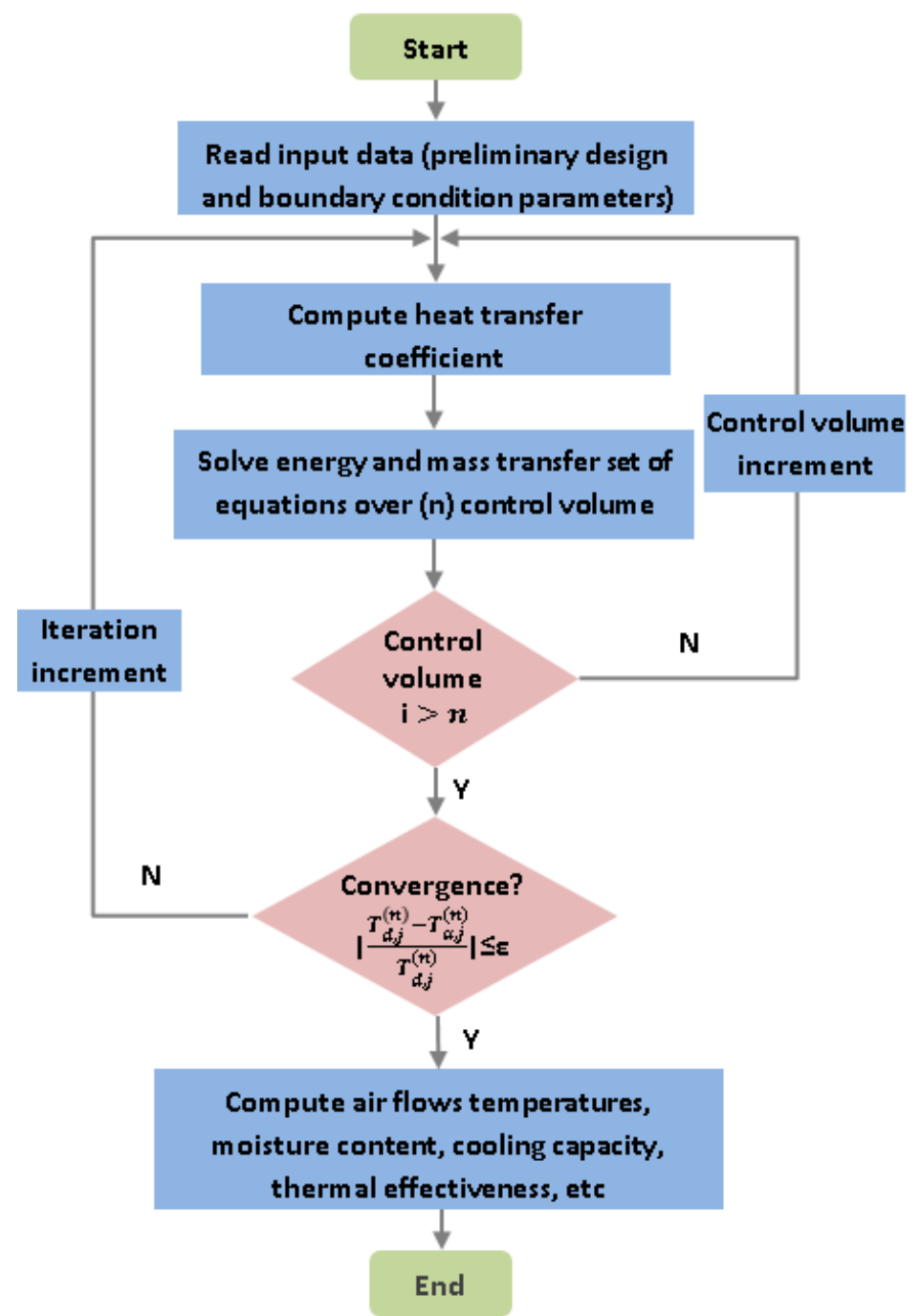

Fig. 4 Computational algorithm flowchart

The iterative solution of the discretised computational model was considered to converge when the absolute temperature difference of the product and working air in $\mathrm{n}^{\text {th }}$ control volume is small. This convergence criterion after iteration, j, can be written as follows:

$$
\left|\frac{T_{d, j}^{(n)}-T_{a, j}^{(n)}}{T_{d, j}^{(n)}}\right| \leq \varepsilon
$$

In this study the temperature difference limit, $\varepsilon$ was taken equal to $3 \times 10^{-3}$, which represents an order of magnitude better than the sensitivity of thermocouples used in measuring the airflow temperature.

\section{Prototype construction and experiment set-up}

A regenerative evaporative cooler described in section 3 was built and tested. The cooler outer casing was made of clear Perspex sheets with the inner space being split into two sections: a lower and upper section which form the dry and wet channel respectively. The heat pipe-ceramic tube modules straddle across both channels with 
the heat pipe finned evaporator located in the dry channel and the condenser-ceramic tube in the wet channel. Fig. 5 (a) shows the assembled system and Fig. 5(b) shows a heat pipe-ceramic tube module.

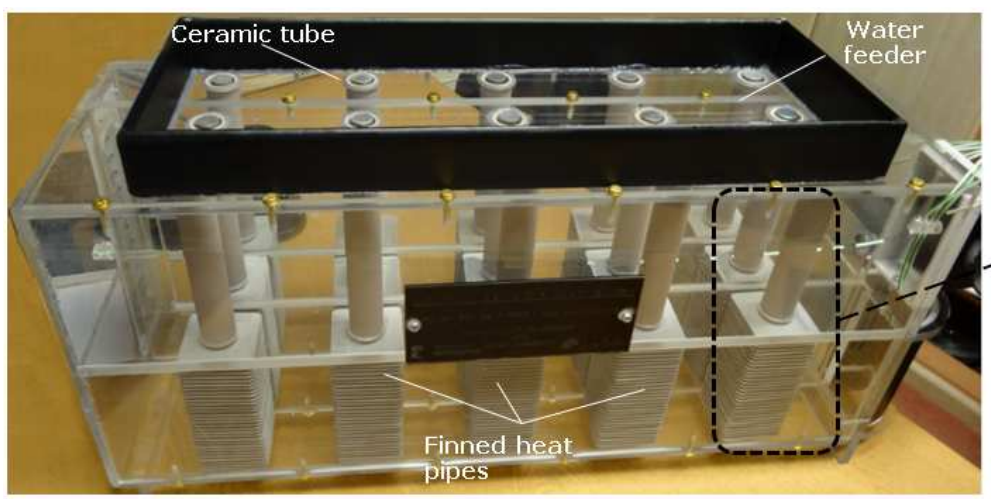

a)

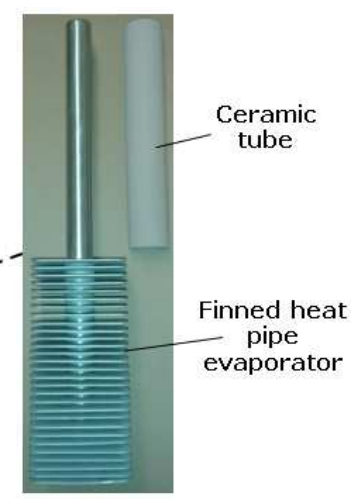

b)

Fig. 5 a) Assembled regenerative cooler b) Heat pipe-ceramic tube module

The heat pipes used in this design were sourced from a local heat pipes manufacturer. The heat pipes specification involves using off-the shelf standard heat pipes with a finned evaporator to augment heat transfer on the air side. The design of the porous ceramic tubes however requires working with a specialist manufacturer of ceramic filters to set up the required sintering temperature and wall thickness to achieve the desired porosity of about $20 \%$. This is essential to ensure the correct wettability and avoid excess water flow and droplet formation on the outer surface of the ceramic tube. The ceramic tube was fitted loosely over the condenser of the heat pipe forming a narrow annular gap which is open at the top end to a water feed container. In this design, it was essential to minimise the number of heat pipe-ceramic tube modules, as these constitute the main cost of the system. The required number of modules was determined so that maximise temperature drop across the heat pipe-porous ceramic tube was obtained which in turn requires that the air discharged at the outlet of the wet channel is fully saturated. The design parameters, dimensions and material specification of the cooler are summarised in Table 3.

Table 3 Main design parameters

\begin{tabular}{ll}
\hline Component & Design parameter / specification \\
\hline Outer casing & Clear Perspex \\
Material & $700 \times 227 \times 300 \mathrm{~mm}$ \\
Length x Width x Height & $5 \mathrm{~mm}$ \\
Wall thickness & $140 \mathrm{~mm}$ \\
Height of dry channel & $140 \mathrm{~mm}$ \\
Height of wet channel & $130 \mathrm{~mm}$ \\
Diameter of product air inlet opening & $100 \mathrm{~mm}$ \\
Diameter of supply air outlet opening & $100 \mathrm{~mm}$ \\
Diameter of working air outlet opening & \\
\hline
\end{tabular}




\begin{tabular}{ll}
\hline Heat pipes & \\
Outer diameter & $\mathrm{d}_{\mathrm{o}}=18 \mathrm{~mm}$ \\
Inner diameter & $\mathrm{d}_{\mathrm{i}}=15.8 \mathrm{~mm}$ \\
vapour space diameter & $\mathrm{d}_{\mathrm{v}}=15.47$ \\
Length of evaporator & $\mathrm{l}_{\mathrm{e}}=130 \mathrm{~mm}$ \\
Length of condenser & $\mathrm{l}_{\mathrm{c}}=155 \mathrm{~mm}$ \\
Length of adiabatic section & $\mathrm{l}_{\mathrm{a}}=10 \mathrm{~mm}$ \\
Wick structure & 2 layered screen mesh \\
Mesh count (number of wires/25.4mm) & $\mathrm{N}_{\mathrm{wk}}=250$ \\
Mesh wire diameter & $\mathrm{d}_{\mathrm{w}}=0.04064 \mathrm{~mm}$ \\
fluid & de-ionised water \\
Number of heat pipes & $\mathrm{n}=15$ \\
\hline Porous Ceramic tubes & \\
Materials compositions & $25.68 \% \mathrm{Al}_{2} \mathrm{O}_{3}, 66.85 \% \mathrm{Si} \mathrm{O}_{2}, 4.03 \%$ \\
& $\mathrm{Albite}, 3.44 \%$ others \\
Length & $150 \mathrm{~mm}$ \\
Inside diameter & $26 \mathrm{~mm}$ \\
Outside diameter & $28 \mathrm{~mm}$ \\
Porosity & $21 \%$ \\
Density & $2300 \mathrm{~kg} / \mathrm{m}^{3}$ \\
Thermal conductivity & $1.5 \mathrm{~W} / \mathrm{mK}$ \\
\hline Other components & \\
Variable speed fan & $\mathrm{EC} \mathrm{centrifugal} \mathrm{fan:} \mathrm{Nominal} \mathrm{power}$ \\
& $85 \mathrm{~W}, \mathrm{speed} 2500 \mathrm{rpm}$, voltage \\
& $220-240 \mathrm{~V}$, frequency $50 \mathrm{~Hz}$ \\
Speed controller & $20 \%$ to $100 \%$ of nominal speed \\
& \\
\hline
\end{tabular}

A fully instrumented laboratory test rig is shown in Fig. 6. At the start of the experiment, the temperature and relative humidity of air inside the environmental chamber (point (1)) is pre-set to the desired level. A speed controlled centrifugal fan draws in air at point (2) to the evaporative cooler through a flexible duct. The hot, dry air is admitted into the dry channel of the cooler at point (3) where it is cooled as it flows over a series of finned evaporators of the heat pipes. At the outlet of the dry channel, a proportion of the cool product air is supplied at point (4) for space cooling whereas the remainder of the cool, dry air enters the wet channel at point (5). In the wet channel, the cool, dry air flows over a successive of wet surfaces of the ceramic tubes and causes water to evaporate and cool the condenser section of the heat pipes. The air is eventually rejected to the outside at point (6) as fully saturated. 


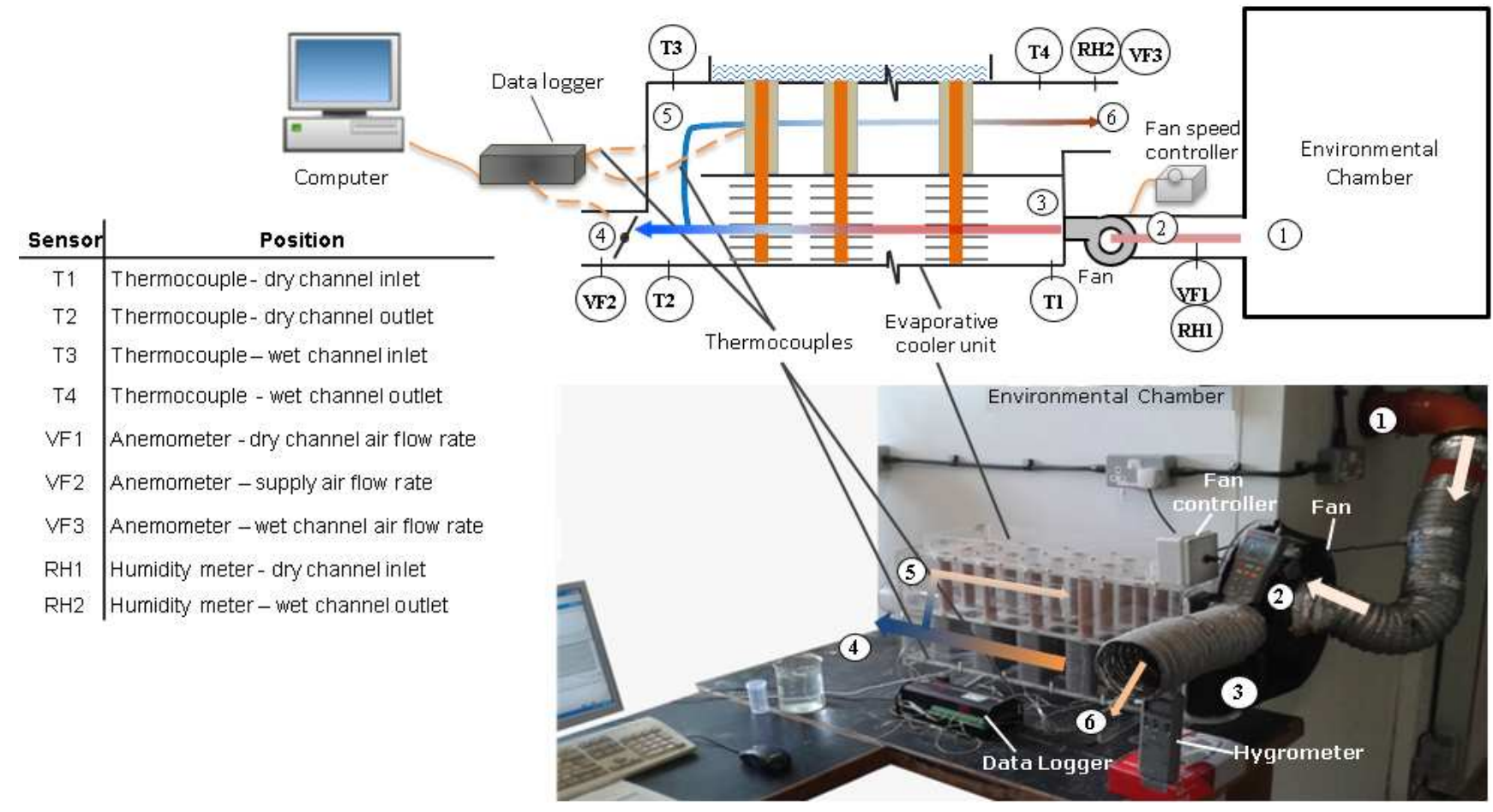

Fig. 6 Experimental test-rig

The experimental test rig was fully instrumented with thermocouples, anemometers, hygrometer and data logging station as shown in Table 4. In practice measuring the air relative humidity using a hygrometer is more convenient. Hence, in all experimental work the airflow was expressed by its relative humidity.

Table 4 Test rig instruments

\begin{tabular}{llll}
\hline Parameter & Instrument/sensor & Range & Accuracy \\
\hline Air velocity & Hotwire anemometer & 0 to $10 \mathrm{~m} / \mathrm{s}$ & $\pm 5 \%$ \\
Temperature & Type K thermocouples & -50 to $+250{ }^{\circ} \mathrm{C}$ & $\pm 0.4 \%$ \\
Relative Humidity & Hygrometer & $10 \%-95 \%$ & $\pm 1 \%$ \\
Water consumption & Electronic scale & 0 to $1000 \mathrm{~g}$ & $\pm 2 \%$ \\
Data Logger & DT500 & & \\
\hline
\end{tabular}

The experimental testing of the regenerative evaporative cooler was performed at various operating conditions of air temperature, relative humidity and airflow rate. The inlet air temperatures was set at 30,35 and $40^{\circ} \mathrm{C}$, relative humidity at 25,35 , and $45 \%$ and working to product air flow rate ratio at $0.25,0.5$ and 0.75 respectively. The product airflow rate in the dry channel was $150 \mathrm{~m}^{3} / \mathrm{h}$ (a corresponding wet channel working airflow rate of 37.5 , 75 and $\left.112.5 \mathrm{~m}^{3} / \mathrm{h}\right)$. 


\section{Results and Discussion}

The experimental measurements were performed under highly controlled laboratory conditions. The effect of the ambient air temperature, humidity and airflow rates on thermal performance of the cooler unit was assessed and compared to the computer model results.

\subsection{Effect of ambient air temperature}

The cooling effectiveness of evaporative coolers are dependent on ambient conditions. The effect of the ambient air temperature on the cooler effectiveness was modelled and measured at constant inlet air relative humidity $\omega_{d, i n}^{(1)}=35 \%$, product air flow rate $\dot{m}_{\mathrm{d}}=150 \mathrm{~m}^{3} / \mathrm{h}$ and airflow ratio $\alpha=\frac{\dot{m}_{a}}{\dot{m}_{d}}=0.5$. Fig. 7 shows that the measured cooler wet bulb effectiveness increased from about 0.7 to 0.84 as ambient inlet air temperature, $T_{d, i n}^{(1)}$, increased from 30 to $40^{\circ} \mathrm{C}$. Similarly, over the same range of operating conditions, the difference in air temperature $\left(T_{d, i n}^{(1)}-\right.$ $\left.T_{d, \text { out }}^{(n)}\right)$ increased from about 7.5 to $10.7^{\circ} \mathrm{C}$. These results follow an expected trend as observed in well-designed evaporative cooling systems. It can also be seen that there is good overall agreement between measured and simulated results with maximum discrepancy of about 11.5 and $9.7 \%$ for wet bulb effectiveness and air temperature difference respectively.

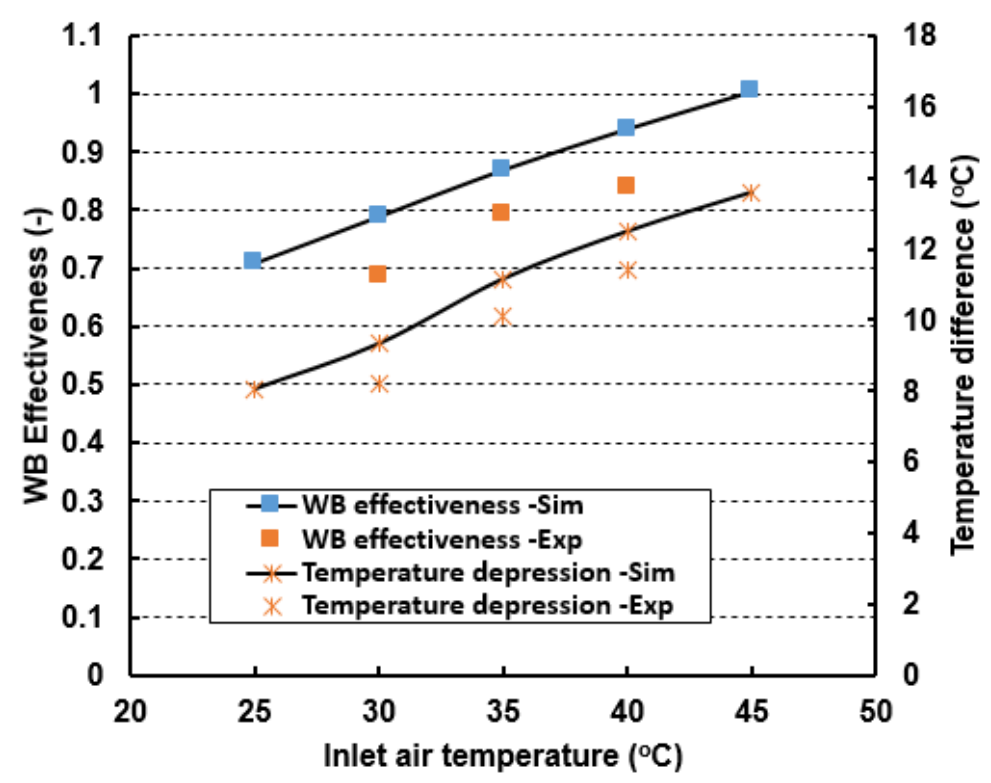

Fig. 7 Effect of dry bulb temperature $\left(R H=35 \%, \dot{m}_{\mathrm{d}}=150 \mathrm{~m}^{3} / h, \alpha=0.5\right)$

\subsection{Effect of ambient air relative humidity}

The same experimental procedure was followed in the measurement of the effect of ambient air humidity. In this measurement, the inlet air humidity, $\omega_{d, i n}^{(1)}$, was set at 25,35 and $45 \%$, while the inlet air temperature was held constant $\left(T_{d, i n}^{(1)}=35^{\circ} \mathrm{C}\right)$, product air flow rate $\dot{m}_{\mathrm{d}}=150 \mathrm{~m}^{3} / \mathrm{h}$ and air flow ratio $\alpha=\frac{\dot{m}_{a}}{\dot{m}_{d}}=0.5$. 
Both simulation and test results indicate that increasing ambient air humidity would lead to an increase of the cooler's effectiveness while the air temperature difference $\left(T_{d, \text { in }}^{(1)}-T_{d, \text { out }}^{(n)}\right)$ would decrease, as shown in Fig. 8(a). The increase in wet bulb effectiveness is an ambiguous contradiction, as higher inlet air humidity should yield lower effectiveness values. This obvious when considering that the wet bulb temperature depression can become very small at high values of moisture content, rendering the value of the denominator in the wet bulb effectiveness equation $\left(\varepsilon_{\mathrm{wb}}=\frac{\mathrm{T}_{\mathrm{db}, \mathrm{in}}^{(1)}-\mathrm{T}_{\mathrm{db}, \text { out }}^{(n)}}{\mathrm{T}_{\mathrm{db}, \mathrm{in}}^{(1)}-\mathrm{T}_{\mathrm{wb}, \mathrm{in}}^{(1)}}\right)$ small. Hence, care must be exercised when using the effectiveness of an evaporative cooler as a measure of performance.

Therefore, in this case other performance indices such as cooling capacity and COP may reflect better the operational advantages of regenerative evaporative cooling systems. The effect of ambient air relative humidity on the specific cooling capacity and COP is presented in Fig. 8(b). The measured specific cooling capacity was evaluated as the cooling effect produced per unit surface area of the wet porous ceramic. This allows customising the cooling capacity to the number of porous ceramic tubes. The COP on the other hand expresses the energy efficiency of the system and is defined as the ratio of the produced cooling effect to the fan power demand corresponding to the air flow rate.

It can be seen that the cooling capacity and COP decrease as ambient air relative humidity increases. The simulation results show that the decline in performance is steepest at air relative humidity above $50 \%$. Additionally, there is consistency between predicted computational model results and experimental measurement with WB effectiveness and air temperature difference $\left(T_{d, \text { in }}^{(1)}-T_{d, o u t}^{(n)}\right)$ margin of error ranging from 9 to $14.7 \%$.

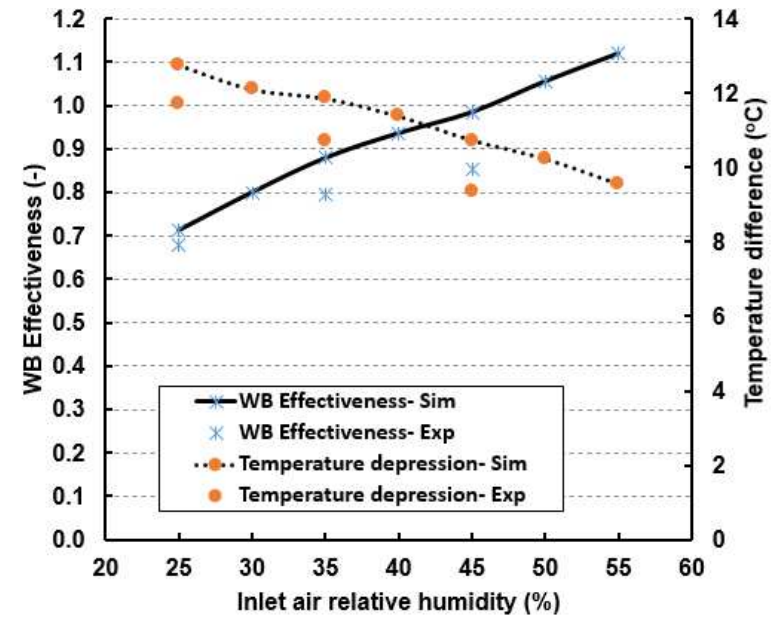

(a)

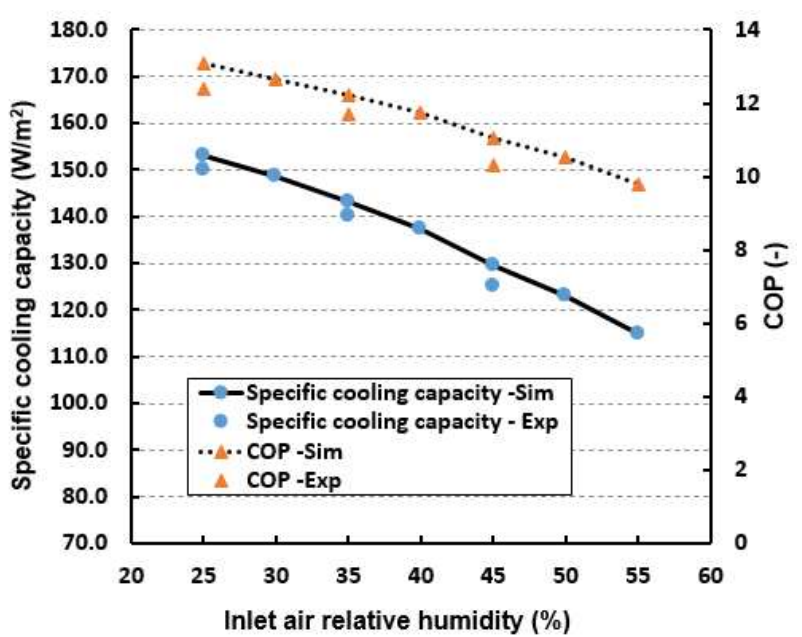

(b)

Fig. 8 Effect of relative humidity a) WB effectiveness and temperature difference b) specific cooling capacity and $\operatorname{COP}\left(T_{d, i n}^{(1)}=35^{\circ} \mathrm{C}, \dot{m}_{d}=150 \mathrm{~m}^{3} / \mathrm{h}, \alpha=0.5\right)$ 


\subsection{Effect of airflow ratio}

Regenerative evaporative cooling systems accomplish significant energy saving, but compared to direct evaporative coolers the saturated, cool air in the wet channel is discharged to outside. Therefore, the discharged cool, saturated air needs to be reduced to a useful minimum. The effect of the amount of air diverted through the wet channel, expressed here, as a ratio of working to product airflow rate, on the cooling capacity and wet bulb effectiveness of the system was measured. The airflow ratio was set to $0.25,0.5$ and 0.75 of the maximum flow rate of $150 \mathrm{~m}^{3} / \mathrm{h}$ while the inlet air temperature and relative humidity were held constant at $35{ }^{\circ} \mathrm{C}$ and $35 \%$, respectively. The profile of computationally modelled and experimentally measured wet bulb effectiveness and cooling capacity of the cooler are illustrated in Fig. 9. It can be seen that the wet bulb effectiveness exhibits maximum values at flow rate ratios of about 0.5 . In contrast, the specific cooling capacity shows an opposite trend in that it peaks at $160 \mathrm{~W} / \mathrm{m}^{2}$ for flow rate ratios below 0.5 and declines steeply at higher flow rate ratios. Therefore, the optimum wet bulb effectiveness and specific cooling capacity were obtained for airflow ratio of the order of 0.5 .

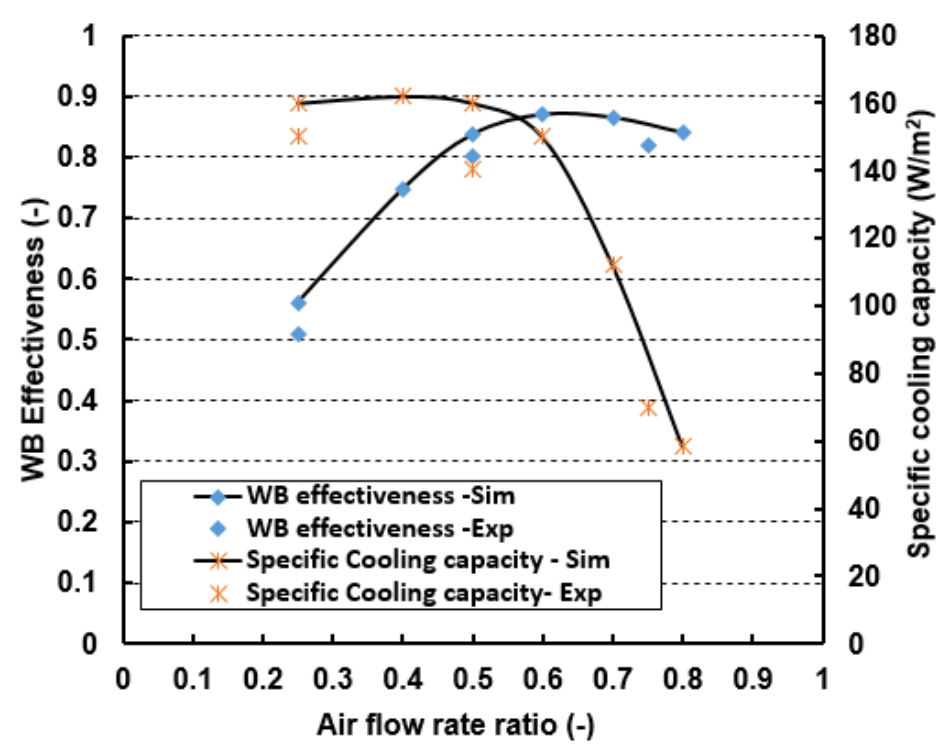

Fig. 9 Effect of flow rate ratio on WB effectiveness and specific cooling capacity $\left(T_{d, \text { in }}^{(1)}=35^{\circ} \mathrm{C}, \dot{m}_{d}=150 \mathrm{~m}^{3} / \mathrm{h}\right.$, $\mathrm{RH}=35 \%)$

\section{Dynamic performance}

This part of the study was evaluated experimentally to understand how the product air temperature responds to changes of airflow rate ratio and ambient inlet air temperature. This was performed by imposing step changes of 
airflow ratio $(0.25,0.5$ and 0.75$)$ and measuring the temperature variation of product and working air at the outlets of the cooler while the inlet air temperature and relative humidity being held constant at $35{ }^{\circ} \mathrm{C}$ and $35 \%$ respectively. Fig. 10 shows that the measured temperature of air at the outlet of the wet and dry channels decreased steeply from the initial value of $35^{\circ} \mathrm{C}$ to 29 and $27.5^{\circ} \mathrm{C}$ respectively as a result of a step change in the amount of air diverted through the wet channel (flow rate ratio change from $\alpha=0$ to 0.25 ). Increasing the airflow rate ratio to 0.5 ensued a further decrease in air temperature at the outlet of the wet and dry channel, settling at a new steady state of 25.95 and $23.97^{\circ} \mathrm{C}$ respectively. Subsequent increase of the airflow rate ratio had very little effect on product air temperature and at $\alpha=0.75$ the air temperature decreased by a mere $1{ }^{\circ} \mathrm{C}$. It can also be seen that the temperature of the surface of the porous ceramic tube $(i=1)$ followed similar step change patterns. Moreover, Fig. 10 shows clearly that the thermal mass of the system has an effect on the outlet air temperature response. The effect can be characterised by the system's time constant, which can be measured to be about 4.2 minutes. This indicates that one of the control strategies of product air temperature could be by varying the airflow ratio.

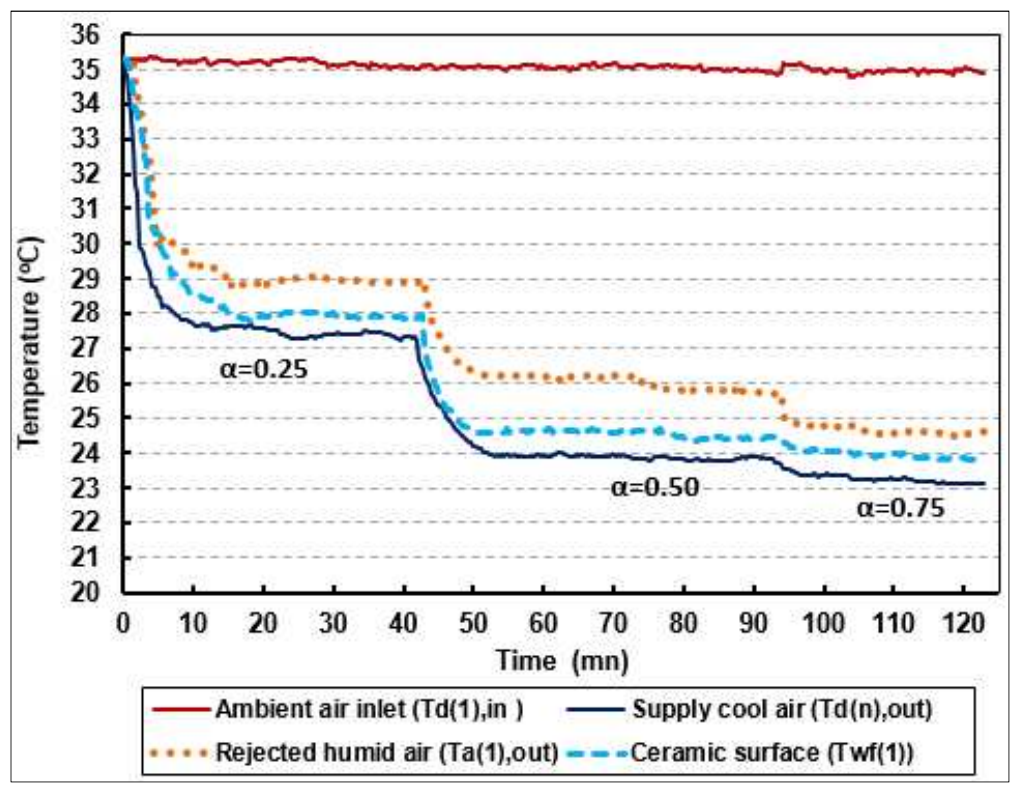

Fig. 10 Dynamic temperature response $\left(T_{d, i n}^{(1)}=35^{\circ} \mathrm{C}, \dot{m}_{d}=150 \mathrm{~m}^{3} / h, \mathrm{RH}=35 \%\right)$

The performance of the prototype evaporative cooler was also measured under a variable ambient air temperature on a harsh summer day with the ambient air temperatures above $30^{\circ} \mathrm{C}$ and having a bell shaped profile, peaking at about $45^{\circ} \mathrm{C}$. The recorded air temperature at the inlet of the dry channel, $\mathrm{T}_{\mathrm{d}, \text { in }}^{(1)}$, outlet of the dry channel, $\mathrm{T}_{\mathrm{d}, \text { out }}^{(\mathrm{n})}$, and outlet of the wet channel, $\mathrm{T}_{\mathrm{a}, \text { out }}^{(1)}$ are presented in Fig. 11. It was found that the evaporative cooler could supply consistently fresh air at temperatures as low as $14^{\circ} \mathrm{C}$ below the ambient. It can also be seen that for ambient air temperatures above $34^{\circ} \mathrm{C}$, the evaporative cooling alone would not be sufficient to provide adequate supply air temperatures. To address the issue and realise maximum energy savings derived from evaporative cooling, one 
possible solution is to combine evaporative cooling and vapour compression as a secondary system to meet remaining peak cooling loads.

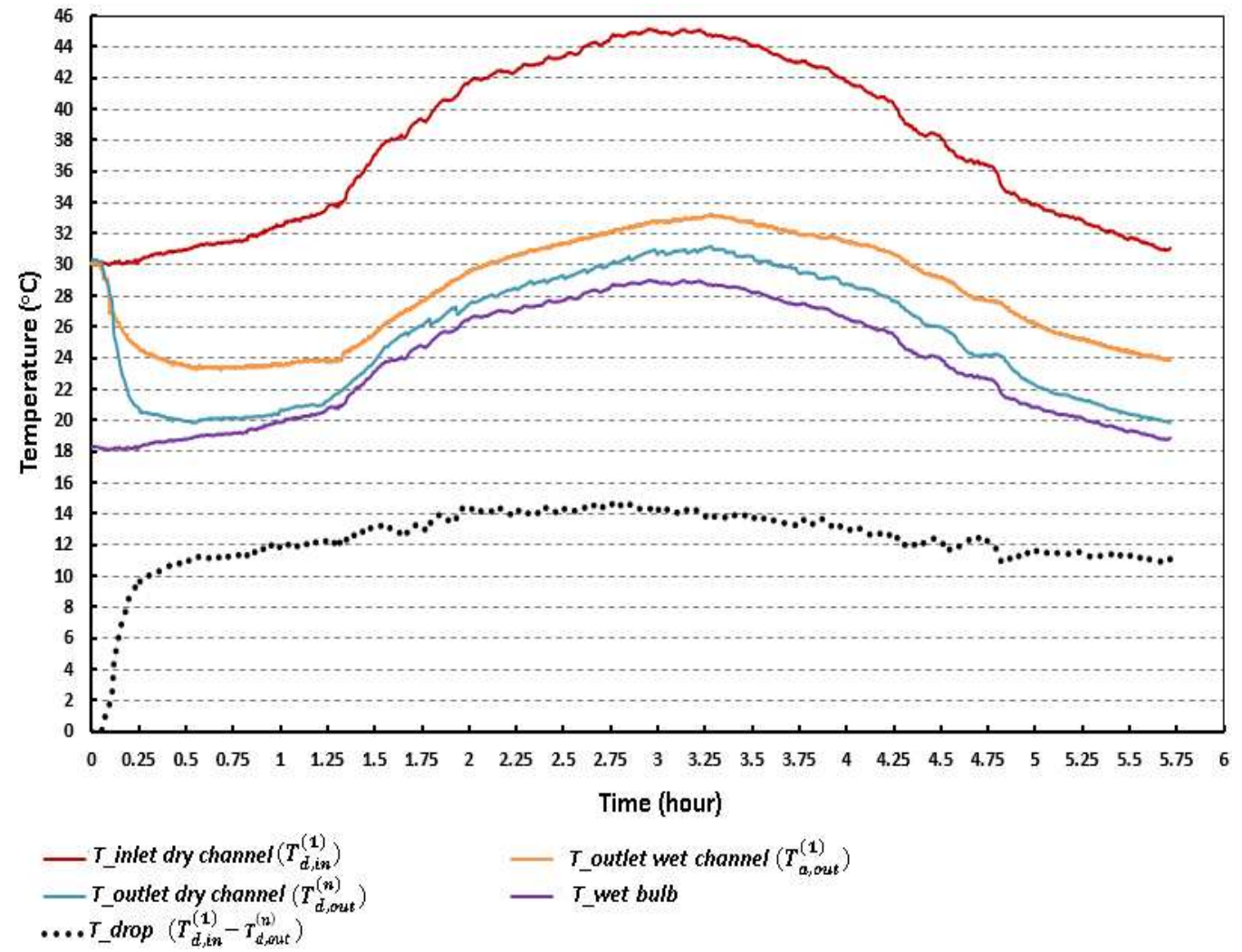

Fig. 11 Dynamic thermal response $\left(\dot{m}_{d}=150 m^{3} / h, \alpha=0.5, \mathrm{RH}=25-30 \%\right)$

\section{Discussion and conclusion}

A regenerative evaporative cooler using an integrated heat pipe and porous ceramic tube arrangement for effective heat and mass transfer was designed, modelled and tested. The performance of the designed cooler was evaluated theoretically and experimentally. The results show that the cooler performed well under simulated weather conditions of hot and dry climates. For example, a steady state ambient air temperature and relative humidity of $35{ }^{\circ} \mathrm{C}$ and $35 \%$ respectively, the system's wet bulb effectiveness was 0.8 , specific cooling capacity $140 \mathrm{~W} / \mathrm{m}^{2}$ and overall COP of 11.43 . It was also shown that the computer model results compare favourably with experimentally recorded data with operating parameters such as temperatures, wet bulb effectiveness, and cooling capacity margin of error being $4.93 \%, 12.92 \%$ and $11.41 \%$ respectively. Furthermore, tests under a dynamic regime of ambient air temperature showed that for temperatures lower than $34^{\circ} \mathrm{C}$ and relative humidity of $30 \%$, the cooler could provide an acceptable level of supply air temperatures in a displacement ventilation and passive cooling strategy for buildings. It is also true that the performance of the cooler is prone to prevailing weather conditions and for higher ambient air temperature and humidity, further cooling and dehumidification measures may be needed. This work can also contribute to future development of regenerative evaporative cooling systems using various types of porous ceramics and heat pipe technology such as flat plate heat pipes/vapour chambers as an alternative to environmentally damaging PVC materials. 
To assess fully the cooling capability of the system, the computational and experimental results need to be verified in a real building with well-defined physical and thermal parameters. Finally, in regions of the world with arid climates, evaporative cooling is a suitable technology that can contribute to a sustainable built environment and provide required thermal comfort when considered as part of a holistic thermal solution approach that combines orientation, fenestration, shadings, and thermal mass of buildings.

\section{Acknowledgement}

This publication was made possible by NPRP grant No. 4 -407 -2 -153 from the Qatar National Research Fund (a member of Qatar Foundation). The statements made herein are solely the responsibility of the authors. 


\section{Nomenclature}

\begin{tabular}{|c|c|}
\hline Symbol & unit \\
\hline$A_{a}$ & Water film surface area, \\
\hline$A_{d}$ & Dry channel heat transfer area \\
\hline $\mathrm{C}_{\mathrm{P}, \mathrm{a}}$ & Moist air specific heat capacity $(\mathrm{J} / \mathrm{kgK})$ \\
\hline $\mathrm{c}_{\mathrm{P}, \mathrm{d}}$ & Dry air specific heat capacity $(\mathrm{J} / \mathrm{kgK})$ \\
\hline $\mathrm{C}_{\mathrm{P}, \mathrm{v}}$ & Water vapour specific heat capacity $(\mathrm{J} / \mathrm{kgK})$ \\
\hline$L_{e}$ & Lewis Number \\
\hline$h_{w f, i n}$ & Inlet water specific enthalpy $(\mathrm{J} / \mathrm{kg})$ \\
\hline$h_{w f, \text { out }}$ & Outlet water specific enthalpy $(\mathrm{J} / \mathrm{kg})$ \\
\hline$h_{f g}$ & Specific latent heat of water vaporisation at $T_{w f}$ temperature $(\mathrm{J} / \mathrm{kg})$ \\
\hline$\dot{m}_{\mathrm{a}}$ & Wet channel working fluid mass flow rate $(\mathrm{kg} / \mathrm{s})$ \\
\hline$\dot{m}_{\mathrm{d}}$ & Dry channel air mass flow rate $(\mathrm{kg} / \mathrm{s})$ \\
\hline$\dot{m}_{\mathrm{w}}$ & water mass flow rate $(\mathrm{kg} / \mathrm{s})$ \\
\hline$Q_{e}$ & heat pipe entrainment limit (W) \\
\hline$Q_{d}$ & Dry channel heat transfer (W) \\
\hline$Q_{c}$ & Heat pipe heat transfer capillary limit (W) \\
\hline$Q_{b}$ & Heat pipe heat transfer boiling limit (W) \\
\hline$Q_{s}$ & Heat pipe heat transfer sonic limit (W) \\
\hline$Q_{v}$ & Heat pipe heat transfer viscous limit (W) \\
\hline$R_{1}$ & Dry channel convective tthermal resistance $\left(\mathrm{m}^{2} \mathrm{~K} / \mathrm{W}\right)$ \\
\hline$R_{2}$ & Wet channel thermal resistance $\left(\mathrm{m}^{2} \mathrm{~K} / \mathrm{W}\right)$ \\
\hline$R_{H P}$ & Heat pipe overall thermal resistance $\left(\mathrm{m}^{2} \mathrm{~K} / \mathrm{W}\right)$ \\
\hline$T_{\mathrm{wf}}$ & Water film temperature $\left({ }^{\circ} \mathrm{C}\right)$ \\
\hline$T_{d, o}$ & Dry Channel inlet ambient air temperature $\left({ }^{\circ} \mathrm{C}\right)$ \\
\hline$T_{\mathrm{a}, \text { out }}$ & Wet channel outlet air temperature $\left({ }^{\circ} \mathrm{C}\right)$ \\
\hline$T_{a, i n}$ & Wet channel inlet air temperature $\left({ }^{\circ} \mathrm{C}\right)$ \\
\hline$T_{\mathrm{a}}$ & Wet channel control volume average air temperature $\left({ }^{\circ} \mathrm{C}\right)$ \\
\hline$T_{\mathrm{d}}$ & dry channel control volume average air temperature $\left({ }^{\circ} \mathrm{C}\right)$ \\
\hline$T_{d, i n}$ & Dry channel inlet air temperature $\left({ }^{\circ} \mathrm{C}\right)$ \\
\hline$T_{d, \text { out }}$ & Dry channel outlet air temperature $\left({ }^{\circ} \mathrm{C}\right)$ \\
\hline$U_{a}$ & Wet channel convective heat transfer coefficient $\left(\mathrm{W} / \mathrm{m}^{2} \mathrm{~K}\right)$ \\
\hline$U_{d}$ & Dry channel heat transfer coefficient $\left(\mathrm{W} / \mathrm{m}^{2} \mathrm{~K}\right)$ \\
\hline \multicolumn{2}{|l|}{ Symbols } \\
\hline$\omega_{a, o u t}$ & Wet channel outlet air moisture content $(\mathrm{kg} / \mathrm{kgd})$ \\
\hline$\omega_{a, i n}$ & Wet channel inlet air moisture content $(\mathrm{kg} / \mathrm{kg})$ \\
\hline$\omega_{\mathrm{a}}$ & Wet channel control volume average air moisture content $(\mathrm{kg} / \mathrm{kg})$ \\
\hline$\omega_{d, o}$ & Dry Channel inlet ambient air moisture content $(\mathrm{kg} / \mathrm{kg})$ \\
\hline$\omega_{\mathrm{wf}}$ & Wet channel saturated air moisture content $(\mathrm{kg} / \mathrm{kg})$ \\
\hline$\sigma_{m}$ & Wet channel mass transfer coefficient $\left(\mathrm{kg} / \mathrm{sm}^{2}\right)$ \\
\hline$\alpha$ & air flow ratio (-) \\
\hline \multicolumn{2}{|l|}{ indices } \\
\hline $\mathrm{i}$ & order of the control volume \\
\hline
\end{tabular}




\begin{tabular}{|l|l|}
\hline$j$ & number of iteration \\
\hline $\mathrm{n}$ & total number of control volumes \\
\hline
\end{tabular}

\section{References}

1. K. Almutairi, G. Thoma, J. Burek, S. Algarni and D. Nutter, Life cycle assessment and economic analysis of residential air conditioning in Saudi Arabia. Energy and Buildings 102 (2015) pp. 370-379.

2. B.F.Yu M.Liu, H.L.Yang, Q. X. Kong, and Y. H. Liu, Review of research on air-conditioning systems and indoor air quality control for human health. International Journal of Refrigeration, 32(1) (2009), pp. 3-20.

3. S. Coldicutt and T. J. Williamson: A Comparison of Domestic Evaporative and Refrigerative Cooling in South Australia, Architectural Science Review, 29(2) (1986) pp. 41-49.

4. Z. Duan, C. Zhan, X. Zhang, M. Mustafa, X. Zhao, B. Alimohammadisagvand and A. Hasan, Indirect evaporative cooling: Past, present and future potentials. Renewable and Sustainable Energy Reviews, 16(9) (2012) pp. 6823-6850.

5. V. S Maisotsenko, A. B Zimmerman, L. D Mikhaylova, and I. M Pechorskaya,. (1977) Method of indirectevaporative air cooling in household electrical appliances. in Proc. of World Electrotechnical Congress. Moscow, USSR,.

6. J. Lee, and D.-Y. Lee, Experimental study of a counter flow regenerative evaporative cooler with finned channels. International Journal of Heat and Mass Transfer, 65(0) (2013) pp. 173-179.

7. X. Zhao, J.M. Li, and S.B. Riffat, Numerical study of a novel counter-flow heat and mass exchanger for dew point evaporative cooling. Applied Thermal Engineering, 28(14-15) (2008) pp. 1942-1951.

8. Z. Duan, X. Zhao, and J. Li, Design, fabrication and performance evaluation of a compact regenerative evaporative cooler: Towards low energy cooling for buildings. Energy, 140(1) (2017) pp. 506-519.

9. V. Maisotsenko, L. E. Gillan, T. L. Heaton, and A. D. Gillan, (2003) Method and plate apparatus for dew point evaporative cooler. US patent No. 6581402B2.

10. L. Elberling, (2006) Laboratory Evaluation of the Coolerado Cooler Indirect Evaporative Cooling Unit. Pacific Gas and Electric Company.

11. C. Zhan, X. Zhao, S. Smith and S.B. Riffat, Numerical study of a M-cycle cross-flow heat exchanger for indirect evaporative cooling. Building and Environment, 46(3) (2011) pp. 657-668.

12. A. Ahmad, , S. Rehman, and L.M. Al-Hadhrami, Performance evaluation of an indirect evaporative cooler under controlled environmental conditions. Energy and Buildings,. 62 (2013) pp. 278-285

13. S. Anisimov, and D. Pandelidis, Theoretical study of the basic cycles for indirect evaporative air cooling. International Journal of Heat and Mass Transfer, 84 (2015) pp. 974-989.

14. E. D. Rogdakis, I . P. Koronaki, and D. N. Tertipis, Experimental and computational evaluation of a Maisotsenko evaporative cooler at Greek climate. Energy and Buildings, 70 (2014) pp. 497-506.

15. M. Jradi, and S. Riffat, Experimental and numerical investigation of a dew-point cooling system for thermal comfort in buildings. Applied Energy, 132(0) (2014) pp. 524-535. 
16. X. Zhao, J.M. Li, and S.B. Riffat, Numerical study of a novel counter-flow heat and mass exchanger for dew point evaporative cooling. Applied Thermal Engineering, 28(14-15) (2008) pp. 1942-1951.

17. X. Zhao, S. Yang, Z. Duan and S. B. Riffat., Feasibility study of a novel dew point air conditioning system for China building application. Building and Environment,. 44(9) (2009) pp. 1990-1999

18. J. Lee, and D.-Y. Lee, Experimental study of a counter flow regenerative evaporative cooler with finned channels. International Journal of Heat and Mass Transfer, 65(0) (2013) pp. 173-179.

19. B. Riangvilaikul, and S. Kumar, An experimental study of a novel dew point evaporative cooling system. Energy and Buildings, 42(5) (2010) pp. 637-644.

20. B. Riangvilaikul, and S. Kumar, Numerical study of a novel dew point evaporative cooling system. Energy and Buildings, 42(11) (2010) pp. 2241-2250.

21. R. Boukhanouf, A. Alharbi, H. G. Ibrahim, O. Amer and M. Worall, Computer modelling and experimental investigation of building integrated sub-wet bulb temperature evaporative cooling system. Applied Thermal Engineering, 115: (2017) pp. 201-211.

22. Z. Duan, C. Zhan, X. Zhao and X. Dong, Experimental study of a counter-flow regenerative evaporative cooler. Building and Environment, 104 (2016) pp. 47-58.

23. J. Lin, K. Thu, T.D. Bui, R.Z. Wang and K.J. Chua, Study on dew point evaporative cooling system with counter-flow configuration. Energy Conversion and Management, 109 (2016) pp. 153-165.

24. F. Bruno, On-site experimental testing of a novel dew point evaporative cooler. Energy and Buildings, 43(12) (2011) pp. 3475-3483.

25. C. Zhan, Z. Duan, X. Zhao, S. Smith and S. Riffat, Comparative study of the performance of the M-cycle counter-flow and cross-flow heat exchangers for indirect evaporative cooling - Paving the path toward sustainable cooling of buildings. Energy, 36(12) (2011) pp. 6790-6805.

26. X. Cui, K.J. Chua, and W.M. Yang, Numerical simulation of a novel energy-efficient dew-point evaporative air cooler. Applied Energy, 136: (2014) pp. 979-988.

27. P. Xu, X. Ma, X. Zhao, K. S. Fancey, Experimental investigation on performance of fabrics for indirect evaporative cooling applications, Building and Environment 110 (2016) 104e114.

28. R. Schiano-Phan and B. Ford (2003) Evaporative cooling using porous ceramic evaporators: product development and generic building integration. The Plan: architecture \& technologies in detail, 4. pp. 9598.

29. J. He, A. Hoyano, Experimental study of practical applications of a passive evaporative cooling wall with high water soaking-up ability, Building and Environment, 46 (2011) 98e108.

30. S.B. Riffat and J. Zhu, Mathematical model of indirect evaporative cooler using porous ceramic and heat pipe. Applied Thermal Engineering, 24(4) (2004) pp. 457-470.

31. S. Riffat and J. Zhu, Experimental investigation of an indirect evaporative cooler consisting of a heat pipe embedded in porous ceramic. Journal of Research, 1 (2003) pp. 46-52.

32. X. J. Wang, X. Huang, and J. M. Wu, Analysis of a novel indirect evaporative cooler with heat pipe heat exchanger. Fluid Machinery, 32(2) (2004) pp. 72-74.

33. B. Halasz, A general mathematical model of evaporative cooling devices. Revue Générale de Thermique, 37(4) (1998) pp. 245-255. 
34. D. Reay, R. McGlen and P. Kew (2013). Heat Pipes Theory, Design and Applications. 6th Edition. Butterworth-Heinemann. 